\title{
(6) OPEN ACCESS \\ Assessment of risk for asthma initiation and cancer and heart disease deaths among patrons and servers due to secondhand smoke exposure in restaurants and bars
}

\author{
Ruiling Liu, ${ }^{1}$ David L Bohac, ${ }^{2}$ Lara A Gundel, ${ }^{3}$ Martha J Hewett, ${ }^{2}$ Michael G Apte, ${ }^{3}$ \\ S Katharine Hammond ${ }^{1}$
}

- Additional material is published online only. To view please visit the journal online (http://dx.doi.org/10.1136/ tobaccocontrol-2012-050831)

1 Department of Environmental Health Sciences, School of Public Health, University of California, Berkeley, California, USA

${ }^{2}$ Center for Energy and Environment, Minneapolis, Minnesota, USA

${ }^{3}$ Department of Indoor Environment, Lawrence Berkeley National Laboratory, Berkeley, California, USA

Correspondence to Dr S Katharine Hammond, Department of Environmental Health Sciences, School of Public Health, University of California, 50 University Hall \#7360, Berkeley,

California 94720-7360, USA; hammondk@berkeley.edu

Received 19 October 2012 Revised 19 December 2012 Accepted 14 January 2013 Published Online First 13 February 2013

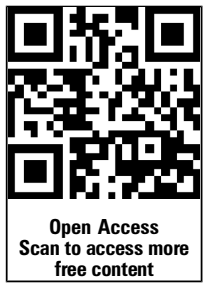

CrossMark

To cite: Liu R, Bohac DL, Gundel LA, et al. Tob

Control 2014:23:332-338.

\section{ABSTRACT}

Background Despite efforts to reduce exposure to secondhand smoke (SHS), only $5 \%$ of the world's population enjoy smoke-free restaurants and bars. Methods Lifetime excess risk (LER) of cancer death, ischaemic heart disease (IHD) death and asthma initiation among non-smoking restaurant and bar servers and patrons in Minnesota and the US were estimated using weighted field measurements of SHS constituents in Minnesota, existing data on tobacco use and multiple dose-response models.

Results A continuous approach estimated a LER of lung cancer death (LCD) of $18 \times 10^{-6}(95 \% \mathrm{Cl} 13$ to $23 \times 10^{-6}$ ) for patrons visiting only designated nonsmoking sections, $80 \times 10^{-6}\left(95 \% \mathrm{Cl} 66\right.$ to $\left.95 \times 10^{-6}\right)$ for patrons visiting only smoking venues/sections and $802 \times 10^{-6}\left(95 \% \mathrm{Cl} 658\right.$ to $\left.936 \times 10^{-6}\right)$ for servers in smoking-permitted venues. An attributable-risk (exposed/ non-exposed) approach estimated a similar LER of $L C D$, a LER of IHD death about $10^{-2}$ for non-smokers with average SHS exposure from all sources and a LER of asthma initiation about 5\% for servers with SHS exposure at work only. These risks correspond to 214 LCDs and 3001 IHD deaths among the general nonsmoking population and 1420 new asthma cases among non-smoking servers in the US each year due to SHS exposure in restaurants and bars alone.

Conclusions Health risks for patrons and servers from SHS exposure in restaurants and bars alone are well above the acceptable level. Restaurants and bars should be a priority for governments' effort to create smoke-free environments and should not be exempt from smoking bans.

\section{BACKGROUND}

Secondhand smoke (SHS) exposure has many adverse health effects and causes over 600000 deaths annually. ${ }^{1}$ Despite efforts to reduce SHS exposure in public places, national smoke-free environment (SFE) regulations for restaurants and bars protect only $5 \%$ of the world's population. ${ }^{2}$ A quarter of the US population remains unprotected by SFE policies in restaurants and 35\% in bars. ${ }^{3}$ Tobacco companies use multiple strategies to oppose SFE policies and sometimes succeed in overturning existing smoking bans; for example, by July 2012 a total of 16 US municipalities had repealed, weakened, or postponed their SFE regulations due to such efforts. ${ }^{4}$ Patronising restaurants and bars may be a predominant source of SHS exposure for those living in smoke-free homes, and occupational SHS exposure of servers may be very high.

Jamrozik estimated that 54 deaths from lung cancer, ischaemic heart disease (IHD) or stroke among hospitality workers were attributed to their workplace SHS exposure. ${ }^{5}$ The published risk assessments ${ }^{6-9}$ are limited to servers only, and the lung cancer or heart disease risks were based on non-representative exposure data; none have estimated health risks for patrons, nor have any examined asthma initiation. A comprehensive risk assessment based on more comprehensive accurate exposure assessment is imperative for policymakers who do not have SFE policies or are considering overturning SFE policies in restaurants and bars.

Steenland described two general approaches to assess risk due to SHS exposure, ${ }^{10}$ a unit risk (UR) or continuous approach based on field measurements and a categorical approach based on relative risks (RR) comparing exposed to non-exposed populations. Both approaches are used in this paper. This paper focuses on the lifetime excess risks (LER) of non-smoking servers and adult patrons for cancer death, IHD death and asthma induction. LER is the difference in lifetime risks/ probability of having a disease between exposed and unexposed populations. LER of cancers due to exposure to various risk factors has been frequently assessed by researchers. ${ }^{11-14}$ Assessment of LER of heart diseases due to SHS exposure has also been applied by the US Occupational Safety and Health Administration (OSHA $)^{15}$ and by Steenland. ${ }^{10}$

\section{METHODS}

Before the October 2007 implementation of SFE policies covering indoor public places and workplaces in Minnesota, a study was conducted to collect detailed SHS exposure data from a statistically representative sample of 65 restaurants and bars that permitted smoking within a 20-mile radius of downtown Minneapolis. Substrata were sampled in proportion to the number of employees working in smoking-permitted venues and the expected SD of SHS concentrations. From February through to September 2007, 2423 shortterm visits (median: $12 \mathrm{~min}$ ) were made to conduct systematically real-time area monitoring of fine particulate matter $\left(\mathrm{PM}_{2.5}\right)$, and to observe the number of lit cigarettes, customers and workers at 3 different times of day (lunch, dinner and evening) on 4 
different day types (Fridays, Saturdays, Sundays and other weekdays) in each venue. These peak-patronage-time visits are used as the basis for estimating exposures. Another $2102 \mathrm{~h}$ visits were conducted at dinner and in the evening to make the same observations, monitor $\mathrm{PM}_{2.5}$ and sample multiple gas phase SHS tracers, including nicotine, 3-ethenylpyridine, pyridine, pyrrole, picoine, quinoline and myosmine; most $(n=186)$ of these were conducted on Fridays and Saturdays. For venues restricting smoking to designated sections $(n=40)$, most sampling was conducted in smoking sections, with observations recorded from both sections. Simultaneous measurements were made in both sections during 16 visits.

\section{Estimate of cancer risk using a continuous approach based on field measurements}

Repace and Lowrey ${ }^{16}$ developed a model to predict the risk of lung cancer death (LCD) due to SHS exposure using $\mathrm{PM}_{2.5}$ as a tracer (SHS- $\mathrm{PM}_{2.5}$ ). The model was validated by predicting epidemiologically derived observational data to within 5\%. They estimated that, for the general US population, the risk of LCD is $5 \times 10^{-5}$ for exposure to $1 \mathrm{mg}$ /day of SHS-PM ${ }_{2.5}$ for 1 year and the LER of LCD can be estimated by equation 1 :

$$
\begin{aligned}
\text { LER of LCD }= & 5 \times 10^{-5}(\mathrm{mg} / \text { day-year })^{-1} \\
& \times \text { Daily dose }(\mathrm{mg} / \text { day }) \times \text { Years } \\
\text { Daily dose }(\mathrm{mg} / \text { day })= & \mathrm{C}_{\text {SHS }-\mathrm{PM}}\left(\mathrm{mg} / \mathrm{m}^{3}\right) \times \mathrm{BR}\left(\mathrm{m}^{3} / \mathrm{h}\right) \\
& \times \text { Time }(\mathrm{h} / \text { day }) \times \mathrm{f}
\end{aligned}
$$

Where daily dose is the exposure dose of SHS-PM 2.5 in $\mathrm{mg} /$ day; years is the number of years exposed to SHS; $\mathrm{C}_{\mathrm{SHS} \text {-PM }}$ is the average concentration of SHS- $\mathrm{PM}_{2.5}$ in $\mathrm{mg} / \mathrm{m}^{3}$ during the period of exposure; BR is the breathing rate in $\mathrm{m}^{3} / \mathrm{h}$; time is the average hours per day exposed to SHS; $\mathrm{f}$ is the days per week exposed divided by 7 days.

The SHS-PM 2.5 concentration was defined as the difference between indoor and outdoor measurements during each visit. The sample was analysed as a 2-stage stratified cluster sample with the first stage consisting of the 9 venue-type/size strata from which 65 venues (clusters) were drawn, and the second stage consisting of 12 day-time strata from which a sample of all possible visits in a year was drawn by quasisystematic sampling. The Complex Samples module of Predictive Analytics SoftWare (PASW) 18.0.0 (SPSS, Inc., Chicago, Illinois, USA) was used to compute statewide averages in smoking-permitted venues/sections for each day-time period, with each measurement or observation weighted by $1 /$ (Venue selection probability $\times$ visit selection probability) (weight 1 ). The SE was computed by the Complex Samples module using a Taylor linearisation formula ${ }^{17}$ that takes the sample design into account. These 'venueweighted' concentrations were further weighted by the number of patrons in smoking venues/sections to estimate the average concentration to which all patrons were exposed in smoking venues/sections (weight 2). The average SHS-PM 2.5 level to which patrons in designated non-smoking section were exposed was estimated by multiplying the SHS- PM $_{2.5}$ level in smoking sections by 0.525 (the ratio of the average non-smoking-section SHS- $\mathrm{PM}_{2.5}$ level to the average smoking-section level according to simultaneous side-by-side measurements during 16 visits), ${ }^{18}$ then weighted by weight 1 and the number of patrons in nonsmoking sections (weight 3 ). To estimate the average SHS-PM 2.5 level to which servers were exposed, the smoking and nonsmoking section concentrations were combined in proportion to the number of patrons in each section (weight 4), assuming that the time spent by servers in each section was proportional to the number of patrons. See online table S1 of the supplementary materials for these weighted concentrations.

To estimate the daily dose, breathing rates (in equation 1) recommended by the US Environmental Protection Agency (EPA) were used: $1.6 \mathrm{~m}^{3} / \mathrm{h}$ for servers at a moderate activity level and $1.0 \mathrm{~m}^{3} / \mathrm{h}$ for patrons at a light activity level. ${ }^{19}$ To avoid overestimating servers' exposure during work, their exposure time was assumed to be $4 \mathrm{~h}$ a day during peak patronage times. OSHA strives to make the workplace safe for everyone, and the agency uses a 45 year working life as standard. Thus, a typical assumption of working 5 days per week for a working life of 45 years was applied. Patrons were assumed to visit a restaurant or bar once every week, with an average time of $86 \mathrm{~min}$ each time $^{20}$ for 60 years.

The risk of cancer due to exposure to volatile organic compounds from SHS (SHS-VOCs) was quantified by using the cancer unit risk estimate (URE) reported by the US EPA ${ }^{21}$ or the equivalent cancer UR reported by the California EPA. ${ }^{22}$ URE and UR both describe the excess cancer risk associated with a daily inhalation exposure to $1 \mu \mathrm{g} / \mathrm{m}^{3}$ of a given chemical for a lifetime of 70 years, assuming $20 \mathrm{~m}^{3}$ /day of inhalation. The LER of cancers can be estimated by equation 2 :

$$
\begin{aligned}
& \text { LER of cancers }=\mathrm{C}_{\text {SHS-VOC }}\left(\mu \mathrm{g} / \mathrm{m}^{3}\right) \times \operatorname{URE} \text { or } \mathrm{UR}\left(\mu \mathrm{g} / \mathrm{m}^{3}\right)^{-1} \\
& \mathrm{C}_{\mathrm{SHS}-\mathrm{VOC}}\left(\mu \mathrm{g} / \mathrm{m}^{3}\right)=\mathrm{C}_{\mathrm{SHS}-\mathrm{PM}}\left(\mu \mathrm{g} / \mathrm{m}^{3}\right) \times\left(\mathrm{EF}_{\mathrm{SHS}-\mathrm{VOC}} / \mathrm{EF}_{\mathrm{SHS}-\mathrm{PM}}\right) \times \mathrm{F}
\end{aligned}
$$

Where $\mathrm{C}_{\mathrm{SHS}-\mathrm{VOC}}$ is the daily average concentration of a SHS-VOC during a 70 year lifetime, $\mu \mathrm{g} / \mathrm{m}^{3}$; URE is the cancer URE reported by the US EPA, $\left(\mu \mathrm{g} / \mathrm{m}^{3}\right)^{-1}$; UR is the cancer UR reported by the California EPA, $\left(\mu \mathrm{g} / \mathrm{m}^{3}\right)^{-1}$; years is the number of years exposed to SHS; $\mathrm{C}_{\mathrm{SHS}-\mathrm{PM}}$ is the average concentration of SHS-PM ${ }_{2.5}$ during peak patronage time, $\mu \mathrm{g} / \mathrm{m}^{3} ; \mathrm{EF}_{\mathrm{SHS}-\mathrm{VOC}}$ and $\mathrm{EF}_{\mathrm{SHS}-\mathrm{PM}}$, are the average emission factors of SHS-VOC and SHS-PM 2.5 from the literature, respectively, $\mu \mathrm{g} /$ cigarette; $\mathrm{F}$ is the adjustment factor, which is $\left(4 \mathrm{~h} /\right.$ day $\times 1.6 \mathrm{~m}^{3} / \mathrm{h} /\left(20 \mathrm{~m}^{3} /\right.$ day $) \times 5$ day $/ 7$ day $\times 45$ years $/ 70$ years $)$ for servers and $(1.4 \mathrm{~h} /$ day $\times 1.0 \mathrm{~m}^{3} / \mathrm{h} /\left(20 \mathrm{~m}^{3} /\right.$ day $) \times 1$ day $/ 7$ day $\times 60$ years $/ 70$ years $)$ for patrons.

The overall cancer risk from exposure to SHS-VOCs was estimated by summing the risk of cancers of all sites from exposure to individual SHS-VOCs. The URE was used when it was available from the US EPA website; otherwise, the UR reported by the California EPA was used. Since SHS-PM 2.5 $_{2}$ was most intensively monitored, and the ratios of simultaneous measurements of SHS-PM 2.5 and SHS-VOC tracers were quite similar to the ratios of their emission factors (EF) reported in the literature (see online table S2 in the supplementary material), exposure to SHS-VOCs was estimated from the ratios of their EFs to $\mathrm{SHS}_{-\mathrm{PM}_{2.5}}$ EF. Nine SHS-VOCs with URE/UR and EF were available, thus the LER of cancers due to SHS-VOCs exposure was estimated as the sum of cancer risk from these nine SHS-VOCs.

\section{Estimate of health risk by attributable risk assessment method (exposed/non-exposed)}

This method has been used to assess disease burden due to SHS exposure worldwide ${ }^{1}$ and in the US. ${ }^{23}$ Briefly, the burden of a specific disease due to SHS exposure was estimated from the population attributable fraction (PAF), defined as the proportional reduction in disease that would occur if the exposure was 
reduced to zero. The attributable burden (AB) of a disease due to SHS exposure can be estimated by equation $3^{123}$ and the attributable risk of death/case can be estimated by equation $4:{ }^{10}$

$$
\begin{aligned}
\mathrm{AB}_{\mathrm{SHS}} & =\mathrm{B}_{\mathrm{ns}} \times \mathrm{PAF}_{\mathrm{SHS}} \\
\mathrm{B}_{\mathrm{ns}} & =\left(\mathrm{B}-\mathrm{AB}_{\mathrm{sm}}\right)-\left(\mathrm{B}-\mathrm{AB}_{\mathrm{sm}}\right) \times \mathrm{p}_{\mathrm{sm}}=\left(\mathrm{B}-\mathrm{AB}_{\mathrm{sm}}\right) \times\left(1-\mathrm{p}_{\mathrm{sm}}\right) \\
\mathrm{PAF}_{\mathrm{SHS}} & =\mathrm{p}_{\mathrm{SHS}}\left(\mathrm{RR}_{\mathrm{SHS}}-1\right) /\left[\mathrm{p}_{\mathrm{SHS}}\left(\mathrm{RR}_{\mathrm{SHS}}-1\right)+1\right]
\end{aligned}
$$$$
\begin{aligned}
\mathrm{AER}_{\mathrm{SHS}} & =\mathrm{AB}_{\mathrm{SHS}} / \mathrm{P}_{\text {risk }} \\
\mathrm{LER}_{\mathrm{SHS}} & =\mathrm{AAR}_{\text {SHS }} \times \text { Years }
\end{aligned}
$$

Where $\mathrm{B}$ is the total number of deaths/cases per year among the whole population; $B_{n s}$ is the number of deaths/cases per year among non-smokers; $\mathrm{AB}_{\mathrm{sm}}$ is the attributable burden of a disease in number of deaths/cases per year among smokers due to smoking; $\mathrm{AB}_{\mathrm{SHS}}$ is the attributable burden of a disease in number of deaths/cases per year among non-smokers due to SHS exposure; $\mathrm{PAF}_{\mathrm{SHS}}$ is the PAF of the disease burden due to SHS exposure among non-smokers; $\mathrm{p}_{\mathrm{sm}}$ is the prevalence of current smoking; $\mathrm{p}_{\mathrm{SHS}}$ is the prevalence of SHS exposure; $\mathrm{RR}_{\mathrm{SHS}}$ is the relative risk of a disease due to SHS exposure among non-smokers; AER $_{\mathrm{SHS}}$ is the annual excess risk of death/ case due to SHS exposure among non-smokers; $\mathrm{P}_{\text {risk }}$ is the population at risk, that is, current non-smokers aged 35 years or older; LER $_{\mathrm{SHS}}$ is the life time excess risk of death/case due to SHS exposure; years is the number of years of exposure during lifetime.

To estimate the number of LCD and IHD deaths due to SHS exposure among non-smoking adults in Minnesota and the US, the latest (2004) disease burden of these two diseases among all adults aged 35 and older ( $\mathrm{B}$ in equation 3 ) and that attributed to smoking $\left(\mathrm{AB}_{\mathrm{sm}}\right.$ in equation 3$)$ were obtained from the US Centers for Disease Control (CDC) website; ${ }^{24}$ the prevalence of current smoking $\left(\mathrm{p}_{\mathrm{sm}}\right)$ in the US and Minnesota and the prevalence of SHS exposure ( $\mathrm{p}_{\mathrm{SHS}}$ ) in the US were obtained from CDC reports. ${ }^{25-27}$ The prevalence of SHS exposure ( $\mathrm{p}_{\mathrm{SHS}}$ ) for Minnesotans relative to the US was assumed to be proportional to the ratios of prevalence of current smoking among the Minnesota population and the US population. RR of LCD or IHD due to SHS exposure $\left(\mathrm{RR}_{\mathrm{SHS}}\right)$ was acquired from the meta-analysis in the US Surgeon General's Report 2006. ${ }^{28}$ Thus, the LER $_{\text {SHS }}$ is the LER of non-smoking adults due to exposure to the average SHS concentration of all sources, not just of restaurants and bars.

The 1992-1994 National Human Activity Pattern Survey for the US determined the percentage of time exposed to SHS that occurred in restaurants and bars was $8.5 \%$ for males and $9.1 \%$ for females. ${ }^{29}$ Although exposure intensity varies in different microenvironments, with SHS levels in bars and restaurants often higher than other indoor locations, ${ }^{30}$ these fractions were applied conservatively to estimate the LCD and IHD deaths due to SHS exposure in restaurants and bars for the general population without adjustment for relative exposure intensities.

Similar approaches were used to estimate the risk of asthma initiation due to SHS exposure at work for never-smoking restaurant and bar servers in Minnesota and the US According to the CDC's Work-Related Lung Disease Surveillance System, ${ }^{31}$ the average prevalence of current asthma (asthma attack in the past 12 months) among never-smoking servers aged 18 and over was 3.8\% (95\% CI 3.0\% to 4.6\%) from 1997 to 2005 . Asthma incidence rate was estimated to be $10 \%$ of the prevalence of current asthma. ${ }^{32}$ Data on restaurant and bar server employment in 2004 was obtained from the US Bureau of Labor Statistics $^{33}$ and the never-smoking rate for the server population was assumed the same as the general population. ${ }^{25} 26$

To estimate the population attributable fraction $\left(\mathrm{PAF}_{\mathrm{SHS}}\right)$ of asthma initiation, the RR was taken from the most relevant study available, ${ }^{34}$ and the prevalence of SHS exposure at work in restaurants and bars was estimated from the percentage of the population not covered by smoking bans for restaurants and/or bars in May 2007 in Minnesota and in January 2012 in the US. ${ }^{3} 35$

\section{RESULTS}

\section{Continuous approach based on field measurements}

The average SHS-PM 2.5 concentration to which patrons were exposed during their visits to smoking venues/sections was $134 \mu \mathrm{g} / \mathrm{m}^{3}$ (SE $12 \mu \mathrm{g} / \mathrm{m}^{3}$ ), the corresponding average for patrons visiting non-smoking sections was $30 \mu \mathrm{g} / \mathrm{m}^{3}$ (SE $4 \mu \mathrm{g}$ ) $\mathrm{m}^{3}$ ) and the weighted average for servers working in smokingpermitted venues was $78 \mu \mathrm{g} / \mathrm{m}^{3}$ (SE $7 \mu \mathrm{g} / \mathrm{m}^{3}$ ).

Based on the risk model developed by Repace and Lowrey, ${ }^{16}$ this exposure corresponds to a LER of LCD $18 \times 10^{-6}(95 \% \mathrm{CI}$ 13 to $23 \times 10^{-6}$ ) for patrons visiting only designated nonsmoking sections and $80 \times 10^{-6}\left(95 \%\right.$ CI 66 to $\left.95 \times 10^{-6}\right)$ for patrons visiting only smoking venues/sections for $1.4 \mathrm{~h}$ per week in 70 years and $802 \times 10^{-6}\left(95 \%\right.$ CI 658 to $\left.936 \times 10^{-6}\right)$ for servers who are exposed for $20 \mathrm{~h}$ per week for 45 years (table 1). The LER of overall cancer death due to exposure to nine SHS-VOCs is $48 \times 10^{-6}$ for servers, $4.8 \times 10^{-6}$ for patrons visiting only smoking venues/sections and $1.1 \times 10^{-6}$ for patrons visiting only designated non-smoking sections; most of these

\begin{tabular}{|c|c|c|c|}
\hline & \multirow[b]{2}{*}{ Servers } & \multicolumn{2}{|l|}{ Patrons } \\
\hline & & Smoking venues/sections & Non-smoking sections \\
\hline Weighted SHS-PM 2.5 levels, mean $(95 \% \mathrm{Cl}), \mu \mathrm{g} / \mathrm{m}^{3}$ & 78 (64 to 91$)$ & $134(110$ to 158$)$ & 30 (22 to 38$)$ \\
\hline Dose response according to Repace and Lowrey ${ }^{16}$ & \multicolumn{3}{|c|}{$5 \times 10^{-5}$ per year for exposure to $1 \mathrm{mg}$ per day } \\
\hline Breathing rates, $\mathrm{m}^{3} / \mathrm{h}$ & 1.6 & 1.0 & 1.0 \\
\hline Average hours per day exposed to SHS, h/day & 4 & 1.4 & 1.4 \\
\hline Days per week exposed to SHS, day/week & 5 & 1 & 1 \\
\hline Number of years exposed to SHS, years & 45 & 60 & 60 \\
\hline Lifetime attributable risk of LCD $(95 \% \mathrm{Cl}), 10^{-6}$ & 802 (658 to 936$)$ & 80 (66 to 95$)$ & 18 (13 to 23$)$ \\
\hline
\end{tabular}
cancers risks were non-lung cancer risks (table 2).

Table 1 Servers' and patrons' risk of lung cancer death (LCD) due to exposure to secondhand smoke in restaurants and bars in Minnesota 
Table 2 Servers' and patrons' cancer risk due to exposure to nine SHS-VOCs in Minnesota restaurants and bars

\begin{tabular}{|c|c|c|c|c|c|c|c|c|c|}
\hline & \multirow[b]{2}{*}{ Carcinogenicity effect } & \multirow[b]{2}{*}{$\begin{array}{l}\text { URE/UR* } \\
\left(10^{-6}\right)\end{array}$} & \multirow[b]{2}{*}{$\begin{array}{l}\text { EFt }(\mu g / \\
\text { cigarette) }\end{array}$} & \multicolumn{2}{|l|}{ Servers } & \multicolumn{2}{|c|}{$\begin{array}{l}\text { Patrons, smoking } \\
\text { venues/sections }\end{array}$} & \multicolumn{2}{|c|}{$\begin{array}{l}\text { Patrons, non-smoking } \\
\text { sections }\end{array}$} \\
\hline & & & & $\begin{array}{l}\text { Level¥ } \\
\left(\mu \mathrm{g} / \mathrm{m}^{3}\right)\end{array}$ & $\begin{array}{l}\text { LER } \S \\
\left(10^{-6}\right)\end{array}$ & $\begin{array}{l}\text { Levelł } \\
\left(\mu g / m^{3}\right)\end{array}$ & $\begin{array}{l}\text { LER } \S \\
\left(10^{-6}\right)\end{array}$ & $\begin{array}{l}\text { Level¥ } \\
\left(\mu \mathrm{g} / \mathrm{m}^{3}\right)\end{array}$ & $\begin{array}{l}\text { LER§ } \\
\left(10^{-6}\right)\end{array}$ \\
\hline \multicolumn{3}{|l|}{$\mathrm{PM}_{2.5}$} & 12471 & 11.5 & - & 1.1 & - & 0.2 & - \\
\hline Acetaldehyde & Nasal cancer in rats & 2.20 & 2292 & 2.11 & 4.6 & 0.20 & 0.5 & 0.04 & 0.1 \\
\hline Acrylonitrile & Lung cancer in humans & 68.0 & 170 & 0.16 & 10.6 & 0.01 & 1.1 & 0.00 & 0.2 \\
\hline Benzene & Leukaemia in humans & 7.80 & 431 & 0.40 & 3.1 & 0.04 & 0.3 & 0.01 & 0.06 \\
\hline 1,3-Butadiene & $\begin{array}{l}\text { Lymphohaematopoietic cancer } \\
\text { in humans }\end{array}$ & 30.0 & 279 & 0.26 & 7.7 & 0.02 & 0.78 & 0.01 & 0.2 \\
\hline Ethylbenzene & Kidney cancer in rats & 2.50 & 131 & 0.12 & 0.3 & 0.01 & 0.03 & 0.00 & 0.01 \\
\hline Formaldehyde & Nasal cancer in humans & 13.0 & 1101 & 1.01 & 13.2 & 0.09 & 1.3 & 0.02 & 0.3 \\
\hline Naphthalene & Nasal cancer in rats & 34.0 & 45 & 0.04 & 1.4 & 0.00 & 0.1 & 0.0009 & 0.03 \\
\hline$N$-Nitrosodimethylamine & Liver cancer in rats & 14000 & 0.57 & 0.00052 & 7.3 & 0.00005 & 0.7 & 0.00001 & 0.2 \\
\hline$N$-Nitrosopyrrolidine & Liver cancer in rats & 600 & 0.10 & 0.00010 & 0.06 & 0.00001 & 0.005 & 0.000002 & 0.001 \\
\hline \multicolumn{2}{|l|}{ Total risk of all cancers } & - & - & - & 48.3 & - & 4.8 & - & 1.1 \\
\hline \multicolumn{2}{|c|}{ Total risk of non-lung cancers } & - & - & - & 37.7 & - & 3.8 & - & 0.8 \\
\hline $\begin{array}{l}\text { *URE/UR: unit risk estima } \\
\text { †Average of EFs reported } \\
\text { fLevel: daily average expc } \\
\text { §LER, lifetime attributable } \\
\text { Only nine SHS-VOCs with } \\
\text { Compounds for which eitl } \\
\text { EF, emission factor; EPA, } \\
\text { smoke; UR, unit risk; URE }\end{array}$ & \multicolumn{8}{|c|}{$\begin{array}{l}\text { Only nine SHS-VOCs with EF (in } \mu \mathrm{g} / \mathrm{cigarette} \text {, available from the literature) and URE or UR available from the US EPA or the California EPA website are included in this table. } \\
\text { Compounds for which either EF or URE/UR were unavailable are not included even though they are known carcinogens. } \\
\text { EF, emission factor; EPA, Environmental Protection Agency; LER, lifetime excess risk; PM } \text { PM. }_{2.5} \text { fine particulate matter; SHS-VOC, volatile organic compounds from SHS; SHS, secondhand } \\
\text { smoke; UR, unit risk; URE, unit risk estimate. }\end{array}$} & ndhand \\
\hline
\end{tabular}

\section{Attributable risk assessment approach (exposed/ non-exposed)}

This approach estimates the LER to be $800 \times 10^{-6}$ (95\% CI 430 to $\left.1180 \times 10^{-6}\right)$ for LCD and $7670 \times 10^{-6}(95 \%$ CI 4830 to $10510 \times 10^{-6}$ ) for IHD death for the general non-smoking population (including patrons and servers), due to exposure to the average SHS concentration of all sources in Minnesota, and $890 \times 10^{-6}\left(95 \%\right.$ CI 480 to $\left.1290 \times 10^{-6}\right)$ for LCD and $12530 \times 10^{-6}\left(95 \%\right.$ CI 8430 to $\left.16620 \times 10^{-6}\right)$ for IHD death in the US (table 3). The LER of asthma initiation is estimated to be $7.2 \%$ (95\% CI $2.4 \%$ to $11.9 \%$ ) for non-smoking servers due to SHS exposure in restaurants and bars in Minnesota and $4.1 \%$ (95\% CI $0.7 \%$ to $7.5 \%$ ) for non-smoking servers in the US. These risks correspond to 3 LCDs and 32 IHD deaths per year among the general non-smoking population, 53 new asthma cases per year among non-smoking servers in Minnesota, 214 LCDs and 3001 IHD deaths per year among the general nonsmoking population and 1420 new asthma cases per year among non-smoking servers in the US (tables 3 and 4).

\section{DISCUSSION}

This paper is the first quantitative risk assessment for restaurant and bar patrons, and of asthma and cancers other than lung cancer. The quality of the underlying exposure data is vastly superior to that in any of the previous SHS risk studies. ${ }^{6-9}$ Measurements from only one US restaurant ${ }^{9}$ were used in any of these SHS risk assessment papers; and all those studies were based on convenience sample of sites or subjects. In contrast, the 65 Minnesota bars and restaurants reported here were chosen systematically to represent venues permitting smoking, and over 2000 measurements were made methodically at different times of day and days of the week.

In addition, three papers $^{6-8}$ used a single dose-response model published by Repace and Lowrey ${ }^{16}$ to estimate the LCD risk and/or IHD risk for workers; one ${ }^{9}$ based its dose-response model on potency factors for diesel exhaust. By contrast, our study used multiple approaches to estimate the health risks and our results converged.

Restaurants and bars are major employers ${ }^{36}$ and are important public places for the general population; $66 \%$ of adults eat out at least weekly. ${ }^{37}$ However, about $30 \%$ of the US population and $95 \%$ of the world population remain unprotected by SFE policies in restaurants and bars. ${ }^{2} 3$

A LER of $1 \times 10^{-6}$ has been considered a de minimis risk, below regulatory concern, while a LER of $3 \times 10^{-4}$ has been considered a de manifestis risk, one of obvious concern that public agencies will usually regulate to mitigate when recognised. ${ }^{38}$ Among workers, a LER of $1 \times 10^{-3}$ has been considered a significant risk, an unsafe level often used as a benchmark by the US. Occupational Safety and Health Administration. Results of this study indicate that SHS-induced LER of LCD for restaurant and bar servers is much higher than the de manifestis risk level, regardless of which dose-response model is used for the estimates. The LER of non-lung cancers due to exposure to SHS-VOCs adds to the LER of LCD and is underestimated because we estimated effects for only nine SHS-VOCs for which $\mathrm{EF}$ and cancer UREs have been reported, while the impact of other carcinogens such as tobacco specific nitrosamines was omitted. The LER of IHD death for restaurant and bar nonsmoking servers is probably much higher than the significant risk. The LER of asthma initiation could be higher than $10 \%$ for non-smoking servers. Other studies around the world have reported higher SHS levels in restaurants and bars than this study. ${ }^{39-42}$ The health risks from SHS exposure in those cities/ countries are expected to be higher.

However, by July 2012 SFE laws already enacted in 16 US municipalities had been repealed, weakened, or postponed ${ }^{4}$ due to anti-smoking ban efforts of the tobacco industry; and a bill proposed to allow smoking in Minnesota bars in 2011. ${ }^{43}$ The significant disease burden imposed on the population from SHS 
Table 3 Attributed death and lifetime attributable risk of LCD and IHD death due to SHS exposure in Minnesota and US, 2004*

\begin{tabular}{|c|c|c|c|c|}
\hline & \multicolumn{2}{|l|}{ Minnesotat } & \multicolumn{2}{|l|}{ USAT } \\
\hline & Lung cancer & $\begin{array}{l}\text { Ischaemic heart } \\
\text { disease }\end{array}$ & Lung cancer & $\begin{array}{l}\text { Ischaemic heart } \\
\text { disease }\end{array}$ \\
\hline Total burden (B), 2004, deaths/year $¥$ & 2352 & 4861 & 157908 & 450043 \\
\hline Attributable burden due to smoking $\left(\mathrm{AB}_{\mathrm{sm}}\right), 2004$, deaths/yearł & 1838 & 776 & 125542 & 72715 \\
\hline Population at risk, current non-smokers aged $35+\left(P_{\text {risk }}\right), 2004 \ddagger$ & \multicolumn{2}{|c|}{$\begin{array}{l}\text { Male: } 1026443 \\
\text { Female: } 1140400\end{array}$} & \multicolumn{2}{|l|}{$\begin{array}{l}\text { Male: } 57058144 \\
\text { Female: } 65584599\end{array}$} \\
\hline Prevalence of current smoking $\left(p_{s m}\right), 2004, \% \S$ & \multicolumn{2}{|c|}{$\begin{array}{l}\text { Male: } 22.0(17.7,26.3) \\
\text { Female: } 19.5(15.8,23.2)\end{array}$} & \multicolumn{2}{|c|}{$\begin{array}{l}\text { Male: } 23.4(21.6,25.2) \\
\text { Female: } 18.5(17.1,19.9)\end{array}$} \\
\hline Prevalence of SHS exposure $\left(p_{\text {SHS }}\right), 2003-2004, \% \uparrow$ & \multicolumn{2}{|c|}{$\begin{array}{l}\text { Male: } 48.8(41.6,55.9) \\
\text { Female: } 46.6(38.8,54.4)\end{array}$} & \multicolumn{2}{|c|}{$\begin{array}{l}\text { Male: } 51.9(44.3,59.5) \\
\text { Female: } 44.2(36.8,51.6)\end{array}$} \\
\hline Relative risk due to SHS exposure $\left(\mathrm{RR}_{\mathrm{SHS}}\right)^{* *}$ & $\begin{array}{l}1.22(1.12 \\
1.32)\end{array}$ & $1.27(1.17,1.37)$ & $1.22(1.12,1.32)$ & $1.27(1.19,1.36)$ \\
\hline Disease burden among non-smokers $\left(B_{n s}\right), 2004$, deaths/year & $\begin{array}{l}410(380, \\
439)\end{array}$ & $3235(3019,3450)$ & $\begin{array}{l}25794(24031 \\
27557)\end{array}$ & $\begin{array}{l}298365(278356 \\
318373)\end{array}$ \\
\hline Overall death rate among non-smokers aged $35+$, per $10^{4}$ & $1.9(1.7,2.1)$ & $14.9(13.5,16.3)$ & $2.1(1.9,2.3)$ & $24.3(22.0,26.6)$ \\
\hline PAF of disease burden among non-smokers due to SHS exposure $\left(\mathrm{PAF}_{\mathrm{SHS}}\right), \%$ & $9.5(5.4,13.6)$ & $11.4(7.3,15.5)$ & $9.5(5.4,13.6)$ & $11.4(7.9,15.0)$ \\
\hline $\begin{array}{l}\text { Attributable burden among non-smokers due to SHS exposure }\left(A B_{S H S}\right) \text {, } \\
\text { deaths/year }\end{array}$ & $39(26,52)$ & $369(273,466)$ & $2412(1630,3195)$ & $\begin{array}{l}34143(26281 \\
42004)\end{array}$ \\
\hline Annual attributable risk due to SHS exposure (AAR $\left.{ }_{S H S}\right), 10^{-6}$ & $\begin{array}{l}17.8(9.5 \\
26.1)\end{array}$ & $170.4(107.3,233.5)$ & $19.7(10.8,28.6)$ & $278.4(187.4,369.3)$ \\
\hline Lifetime attributable risk due to SHS exposure for 45 years (LER SHS $_{\text {S }}, 10^{-6}$ & $\begin{array}{l}800(430 \\
1180)\end{array}$ & $7670(4830,10510)$ & $890(480,1290)$ & $12530(8430,16620)$ \\
\hline $\begin{array}{l}\text { Percentage of SHS exposure in restaurants and bars of total SHS exposure in } \\
\text { terms of time, \%†† }\end{array}$ & $\begin{array}{l}\text { Male: } 8.5 \\
\text { Female: } 9.1\end{array}$ & & $\begin{array}{l}\text { Male: } 8.5 \\
\text { Female: } 9.1\end{array}$ & \\
\hline Deaths attributed to SHS exposure in restaurants and bars, no./year & $3(2.6,4.3)$ & $32(26,38)$ & $214(164,263)$ & $3001(2512,3490)$ \\
\hline \multicolumn{5}{|c|}{ 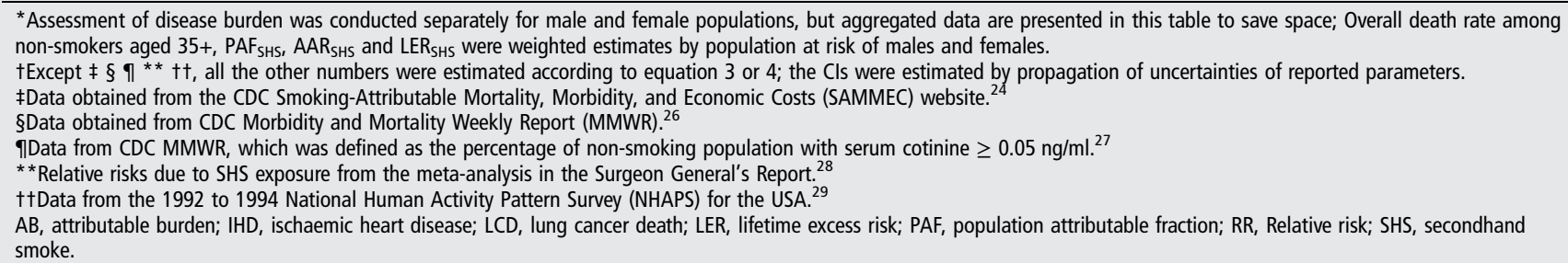 } \\
\hline
\end{tabular}

exposure in restaurants and bars, as reported herein, supports the priority that should be accorded SFE regulation in these venues.

To oppose comprehensive smoking bans in restaurants and bars, the tobacco industry advocates designated non-smoking sections. Unfortunately, this approach offers limited protection for non-smokers, especially for non-smoking servers, who must serve customers in both sections. Our study showed that the LER of LCD is more than 10 times the de minimis risk even for non-smoking patrons who visit only designated non-smoking sections once a week during their lifetime; furthermore the LER of IHD death is substantially higher.

The estimated overall IHD death rate among general nonsmokers aged 35 and over in the US in this study $\left(24.3 \times 10^{-4}\right.$ in table 3 ) is quite close to the IHD death rate among general never-smokers reported in four cohort studies ${ }^{44}$ weighted by the age and gender specific non-smoking population of 35 and over in 2004 , which is $212 \times 10^{-5}$. The consistency between these indicates that the risk assessment and the underlying assumptions used in this study are reasonable and reliable.

The CIs reported in this study reflect only the variations of measured SHS levels or the reported uncertainties of related parameters used in this study and do not encompass all uncertainty of this risk assessment. The variance of servers' and patrons' exposure to SHS-PM 2.5 in restaurants and bars in Minnesota was relatively well characterised by the selection and weighting of the venues and the inclusion of multiple measurements taken during different times of a day and days of the week. Servers and patrons are transient populations with a high turnover, the LER estimated in this study is likely to overestimate the risk for servers and patrons who are not exposed as long as assumed. However, regulations should protect those who do make careers as servers, as well as those who visit regularly. A study reported a current smoking rate of $44.5 \%(95 \%$ CI $35.9 \%$ to $53.1 \%$ ) among servers aged 17 years and over and of $28.3 \%$ (95\% CI $26.9 \%$ to $29.8 \%$ ) among the general adult population from $1988-1994 .^{45}$ Thus by using the proportion of current non-smokers of the general population, the number of new asthma cases attributed to SHS exposure for non-smoking servers may be overestimated, however, the individual lifetime risk remains the same.

Underestimation of these health risks may arise from assuming servers are occupationally exposed to SHS only $4 \mathrm{~h}$ per day and that patrons are exposed only $86 \mathrm{~min}$ per week; longer workdays or more frequent patronage in these venues would increase the risk. Only nine SHS-VOCs were included in the URE while other carcinogens were disregarded due to lack of potency or emission data. When using the attributable risk assessment approach, we assumed that SHS exposure levels in restaurants and bars were similar to the average concentration of all sources for the population. In addition, the risks for only three of the multiple diseases caused by SHS exposure were evaluated, while other health outcomes, for 
Table 4 Attributed cases and lifetime attributable risk of asthma initiation among never smoking servers due to SHS exposure at work in restaurants and bars in Minnesota and in US, 2004*

\begin{tabular}{|c|c|c|}
\hline & Minnesotat & USAT \\
\hline Number of restaurant and bar servers employed, $2004 \ddagger$ & 63300 & 2700590 \\
\hline Never smoking rate, $2004, \% \S$ & $52.5(49.2,55.8)$ & 57.6 \\
\hline Prevalence of current asthma among never smoking restaurant and bar servers, \%ף & $3.8(3.0,4.6)$ & $3.8(3.0,4.6)$ \\
\hline New asthma cases among never smoking restaurant and bar servers $\left(B_{n s}\right)$, cases/year ** & $126(104,148)$ & $5911(4861,6961)$ \\
\hline Percentage of population covered by smoke-free restaurants and/or bars $\left(1-\mathrm{p}_{\mathrm{SHS}}\right), \% \dagger \dagger$ & $38.1(35.2,41.0)$ & $\begin{array}{l}\text { Restaurants: } 74.5 \\
\text { Bars: } 63.7\end{array}$ \\
\hline Relative risk of asthma initiation due to SHS exposure $\left(\mathrm{RR}_{\mathrm{SHS}}\right) \neq \ddagger$ & $2.16(1.26,3.72)$ & $2.16(1.26,3.72)$ \\
\hline Population at risk, never smoking restaurant and bar servers $\left(P_{\text {risk }}\right)$ & $33233(31558,34907)$ & 1555540 \\
\hline PAF of new asthma cases among never smoking restaurant and bar servers due to SHS exposure $\left(\right.$ PAF $\left._{\text {SHS }}\right), \%$ & $41.8(16.0,67.6)$ & $24.0(4.7,43.3)$ \\
\hline New asthma cases attributed to SHS exposure $\left(A R_{S H S}\right)$, cases/year & $53(25,80)$ & $1420(449,2390)$ \\
\hline Annual attributable risk of asthma initiation due to SHS exposure (AAR SHS $_{1}, 10^{-6}$ & $1588(542,2635)$ & $913(153,1672)$ \\
\hline $\begin{array}{l}\text { Lifetime attributable risk of asthma initiation for restaurant and bar servers due to SHS exposure at work for } \\
45 \text { years }\left(\text { LER }_{S H S}\right), \%\end{array}$ & $7.2(2.4,11.9)$ & $4.1(0.7,7.5)$ \\
\hline \multicolumn{3}{|c|}{ 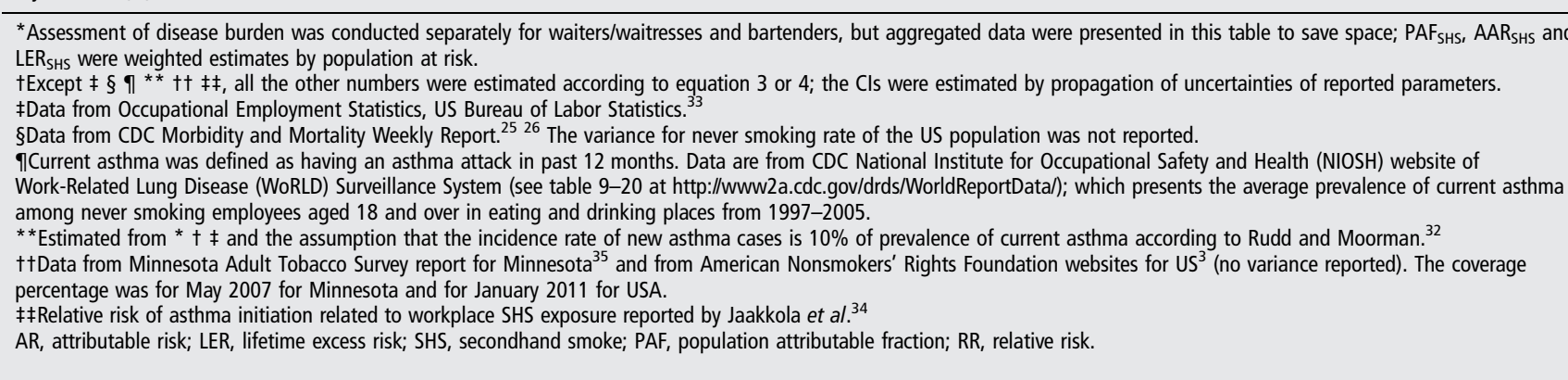 } \\
\hline
\end{tabular}

example, breast cancer for young non-smoking servers, acute heart disease events, acute respiratory irritations for children, etc., were not included due to limited data to quantify these risks. Furthermore, we used a higher percentage of population covered by smoke-free restaurants and bars than would have been the case in earlier years, which can underestimate the total disease burden among the population due to SHS exposure in restaurants and bars.

The most important assumption in this risk assessment is that the association between SHS and the diseases of interests (lung cancer, IHD and asthma initiation among non-smokers) is causal. The causal relationships have been supported by several authority reports. ${ }^{28} 4647$ This risk assessment also assumes that current SHS exposure levels have not changed during the lifetime for servers and patrons. In reality it has probably decreased. Mean air nicotine concentrations measured in restaurants and bars before 1999 ranged from $3-8 \mu \mathrm{g} / \mathrm{m}^{3}$ as reported by Hammond, ${ }^{48}$ which is higher than $3 \mu \mathrm{g} / \mathrm{m}^{3}$ (95\% CI 0 to $7 \mu \mathrm{g} / \mathrm{m}^{3}$ ) as measured in the Minnesota study in $2007 .{ }^{49}$ Thus, the current risk assessment probably underestimated the LER of servers and patrons due to SHS exposure in restaurants and bars. Another important assumption is the use of a linear dose-response relationship when using the continuous risk assessment approach. Because there is no threshold effect from SHS exposure, this assumption is reasonable according to the US EPA risk assessment guidelines. ${ }^{50}$

\section{CONCLUSIONS}

Different risk assessment approaches all revealed that the health risk for patrons visiting smoking restaurants and bars is well above the acceptable level, and that for servers exceeds the 'significant risk' level. This study provides strong evidence that smoking should be banned in hospitality venues to protect the public's health.

\section{What this paper adds}

- Secondhand smoke (SHS) exposure can cause multiple diseases, and SHS levels in restaurants and bars are often higher than in many other public places, however, few studies have comprehensively examined the health risks due to SHS exposure in restaurants and bars.

- Comprehensive smoke bans are the most effective way to protect people from SHS exposure, however, only $5 \%$ of the world's population enjoy smoke-free restaurants and bars, and there continue to be efforts by tobacco companies to remove or weaken existing smoking bans.

- Based on more comprehensive and accurate exposure assessment than the literature, this paper is the first to assess restaurant and bar patrons' health risks of cancers and heart diseases and servers' health risks of asthma initiation due to SHS exposure in restaurants and bars.

- This paper estimated the number of lung cancer and ischaemic heart disease deaths and new asthma cases among the Minnesota and the US populations due to SHS exposure in restaurants and bars alone.

- The results indicate that exposure to SHS in restaurants and bars alone can impose significant health risks to servers and patrons, and restaurants and bars should not be exempted from smoking bans.

Contributors RL, MGA and SKH made substantial contributions to conception and design of the study; DLB, LAG and MJH made substantial contributions to acquisition of data; RL, MJH and MGA were involved in analysing the data and drafting the manuscript; SKH made substantial contributions to interpretation of data and significant revision of the draft for important intellectual content; all authors gave final approval of the version to be published. 
Funding This research project was funded in part by ClearWay Minnesota through Grant Number RC 2006-0050 and in part by Dr William Cahan Distinguished Professor Award to SKH from the Flight Attendants Medical Research Institute.

\section{Competing interests None.}

Provenance and peer review Not commissioned; externally peer reviewed.

Open Access This is an Open Access article distributed in accordance with the Creative Commons Attribution Non Commercial (CC BY-NC 3.0) license, which permits others to distribute, remix, adapt, build upon this work non-commercially, and license their derivative works on different terms, provided the original work is properly cited and the use is non-commercial. See: http://creativecommons.org/licenses/by-nd/3.0/

\section{REFERENCES}

1 Oberg M, Jaakkola MS, Woodward A, et al. Worldwide burden of disease from exposure to second-hand smoke: a retrospective analysis of data from 192 countries. Lancet 2011;377:139-46.

2 WHO. World Health Organization report on the global tobacco epidemic, 2009: implementing smoke-free environments. 2009 (cited 20 0ct 2010). http://www. who.int/tobacco/mpower/2009/en (accessed 15 Sep 2010).

3 ANRF. Summary of 100\% smokefree state laws and population protected by $100 \%$ US smokefree laws. Berkeley, CA: American Nonsmokers' Right Foundation, 2012 (cited 20 January 2012). http://www.no-smoke.org/pdf/SummaryUSPopList.pdf (accessed 18 Jan 2012).

4 ANRF. Local 100\% smokefree laws in all workplaces, restaurants, and bars: effective by year. Berkeley, CA: American Nonsmokers' Right Foundation, 2012 (updated 1 July 2012). http://www.no-smoke.org/pdf/current_smokefree_ ordinances by year.pdf (accessed 17 Sep 2012).

5 Jamrozik K. Estimate of deaths attributable to passive smoking among UK adults: database analysis. BMJ 2005;330:812-15.

6 Siegel M, Skeer M. Exposure to secondhand smoke and excess lung cancer mortality risk among workers in the " 5 B's": bars, bowling alleys, billiard halls, betting establishments, and bingo parlours. Tob Control 2003;12:333-8.

7 Lopez MJ, Nebot M, Juarez 0 , et al. Estimation of the excess of lung cancer mortality risk associated to environmental tobacco smoke exposure of hospitality workers. Medicina Clinica 2006;126:13-14.

8 Hedley AJ, McGhee SM, Repace JL, et al. Risks for heart disease and lung cancer from passive smoking by workers in the catering industry. Toxicol Sci 2006;90:539-48.

9 El-Hougeiri N, El Fadel M. Risk assessment of occupational exposure to environmental tobacco smoke emissions. Indoor Built Environ 2002;11:83-94.

10 Steenland K. Risk assessment for heart disease and workplace ETS exposure among nonsmokers. Environ Health Persp 1999;107:859-63.

11 Chen Y, Ahsan H. Lifetime excess risk of internal cancers due to arsenic exposure among Bangladesh population. Am J Epidemiol 2002;155:s19.

12 Chodick G, Ronckers CM, Shalev V, et al. Excess lifetime cancer mortality risk attributable to radiation exposure from computed tomography examinations in children. Isr Med Assoc J 2007;9:584-7.

13 Maertens RM, Yang XF, Zhu JP, et al. Mutagenic and carcinogenic hazards of settled house dust I: Polycyclic aromatic hydrocarbon content and excess lifetime cancer risk from preschool exposure. Environ Sci Technol 2008:42:1747-53.

14 Vaeth M, Pierce DA. Calculating excess lifetime risk in relative risk models. Environ Health Persp 1990;87:83-94.

15 OSHA. Indoo Air Quality: Proposed Rule, 29 CFR Parts 1910, 1915, 1926, and 192B. Fed Reg 1994;59:15968-6039.

16 Repace JL, Lowrey AH. A quantitative estimate of nonsmokers lung-cancer risk from passive smoking. Environ Int 1985;11:3-22.

17 Woodruff RS. A simple method for approximating variance of a complicated estimate. J Am Stat Assoc 1971;66:411-14.

18 Bohac DL, Hewett MJ, Kapphahn KI, et al. Secondhand smoke exposure in the nonsmoking section: how much protection? Nicotine Tob Res Published Online First 13 Dec 2012 doi:10.1093/ntr/nts263

19 US EPA. Exposure factors handbook (final report). Washington, DC: U.S. Environmental Protection Agency, 1997. EPA/600/P-95/002F a-c.

20 Tsang AM, Klepeis NE. Descriptive statistics tables from a detailed analysis of the National Human Activity Pattern Survey (NHAPS) data. Washington, DC: U.S. Environmental Protection Agency, 1996.

21 US EPA. Integrated Risk Information System (IRIS): A-Z List of Substances. 2011 (cited 30 January 2011). http://cfpub.epa.gov/ncea/iris/index.cfm?fuseaction=iris. showSubstancelist (accessed 30 Jan 2011).

22 Cal/EPA OEHHA. Appendix A: hot spots unit risk and cancer potency values. 2009 (cited 21 December 2010). http://www.oehha.ca.gov/air/hot_spots/2009/AppendixA.pdf (accessed 18 Oct 2010).
23 CDC. Smoking-attributable mortality, years of potential life lost, and productivity losses—United States, 2000-2004. MMWR 2008;57:1226-8.

24 CDC. Smoking-Attributable Mortality, Morbidity, and Economic Costs (SAMMEC). 2010a (cited 23 Jan 2011). https://apps.nccd.cdc.gov/sammec/index.asp (accessed 18 Oct 2010).

25 CDC. State-specific prevalence of cigarette smoking and quitting among adults -United States, 2004. MMWR 2005b;54:1124-7.

26 CDC. Cigarette smoking among adults—United States, 2004. MMWR 2005a; 54:1121-4.

27 CDC. Vital signs: nonsmokers' exposure to secondhand smoke — United States, 1999-2008. MMWR 2010b;59:1141-6.

28 USDHHS. U.S.Department of Health and Human Services. The health consequences of involuntary exposure to tobacco smoke: a report of the surgeon general. Atlanta, GA: U.S. Department of Health and Human Services, Centers for Disease Control and Prevention, coordinating Center for Health Promotion, National Center for Chronic Disease Prevention and Health Promotion, Office on Smoking and Health, 2006.

29 Klepeis NE, Tsang AM, Behar JV. Analysis of the National Human Activity Pattern Survey (NHAPS) respondents from a standpoint of exposure assessment. Washington, DC: US Environmental Protection Agency, 1995.

30 Siegel M. Involuntary Smoking in the Restaurant Workplace - a Review of Employee Exposure and Health-Effects. JAMA-J Am Med Assoc 1993;270:490-3.

31 CDC/NIOSH. Work-Related Lung Disease (WoRLD) Surveillance System. 2008 (cited 25 October 2010). http://www2a.cdc.gov/drds/WorldReportData/ (accessed 18 Oct 2010).

32 Rudd RA, Moorman JE. Asthma incidence: data from the National Health Interview Survey, 1980-1996. J Asthma 2007:44:65-70.

33 US BLS. Occupational Employment Statistics. Bureau of Labor Statistics, United States Department of Labor. 2011 (cited 10 December 2010). http://www.bls.gov/ oes/oes_dl.htm (accessed 10 Dec 2011).

34 Jaakkola MS, Piipari R, Jaakkola $\mathrm{N}$, et al. Environmental tobacco smoke and adult-onset asthma: a population-based incident case-control study. Am J Pub Health 2003;93:2055-60.

35 Minnesota Department of Health. Creating a healthier Minnesota: progress in reducing tobacco Use. Minneapolis, MN: ClearWay Minnesota SM, Blue Cross and Blue Shield of Minnesota and Minnesota Department of Health, 2008.

36 US. BLS. Career Guide to Industries, 2010-11 Edition, Food Services and Drinking Places. Bureau of Labor Statistics, U.S. Department of Labor. 2011 (cited 11 March 2011). http://www.bls.gov/oco/cg/cgs023.htm (accessed 1 Mar 2011).

37 Pew Research Cener. Eating More; Enjoying Less. 2006 (cited 20 Sep 2010). pewresearch.org/assets/social/pdf/Eating.pdf (accessed 7 Sep 2010).

38 Travis Crouch, Milson R, et al. Cancer risk management: a review of 132 regulatory decisions. Environ Sci Technol 1987;21:415-20.

39 Navas-Acien A, Peruga A, Breysse $P$, et al. Secondhand tobacco smoke in public places in Latin America, 2002-2003. JAMA-J Am Med Assoc 2004; 291:2741-5.

40 Hyland A, Travers MJ, Dresler C, et al. A 32-country comparison of tobacco smoke derived particle levels in indoor public places. Tob Control 2008;17:159-65.

41 Lopez MJ, Nebot M, Albertini M, et al. Secondhand smoke exposure in hospitality venues in Europe. Environ Health Persp 2008;116:1469-72.

42 Liu RL, Yang Y, Travers MJ, et al. A cross-sectional study on levels of secondhand smoke in restaurants and bars in five cities in China. Tob Control 2011;20:397-402.

43 Minneapolis St. Paul Business Journal. Bill would repeal smoking ban in MN bars. 2011 (updated 25 January; cited 10 March 2012). http://www.bizjournals.com/ twincities/morning_roundup/2011/01/bill-would-repeal-smoking-ban-in-mn-bars. html (accessed 10 Mar 2012).

44 Steenland K. Passive smoking and the risk of heart disease. JAMA-J Am Med Assoc 1992;267:94-9.

45 Bang KM, Kim JH. Prevalence of cigarette smoking by occupation and industry in the United States. Am I Ind Med 2001;40:233-9.

46 IARC. Tobacco smoke and involuntary smoking (IARC monograph 83). Lyon, France: World Health Organization, 2004

47 Cal/EPA. Proposed Identification of Environmental Tobacco Smoke as a Toxic Air Contaminant. Sacramento, CA: California Environmental Protection Agency Air Resources Board and Office of Environmental Health Hazard Assessment, 2005.

48 Hammond SK. Exposure of US workers to environmental tobacco smoke. Environ Health Perspect 1999;107:329-40.

49 Bohac DL, Hewett MJ, Kapphahn KI, et al. Secondhand smoke exposure for Minnesota bars and restaurants. Minneapolis, MN: Center for Energy and Environment, 2010

50 US EPA. Human Health Risk Assessment. 2012 (updated July 2012; cited 15 Dec 2012). http://www.epa.gov/riskassessment/health-risk.htm (accessed 15 Dec 2012). 